\title{
Source process of the 12 May 2008 Wenchuan, China, earthquake determined by waveform inversion of teleseismic body waves with a data covariance matrix
}

\author{
Yuji Yagi ${ }^{1}$, Naoki Nishimura ${ }^{2}$, and Amato Kasahara ${ }^{2}$ \\ ${ }^{1}$ Faculty of Life and Environmental Sciences, University of Tsukuba, Ten' nodai 1-1-1, Tsukuba 305-8572, Japan \\ ${ }^{2}$ Graduate School of Life and Environmental Sciences, University of Tsukuba, Ten' nodai 1-1-1, Tsukuba 305-8572, Japan
}

(Received March 2, 2012; Revised May 9, 2012; Accepted May 14, 2012; Online published August 2, 2012)

\begin{abstract}
We have estimated the spatio-temporal slip distribution of the 12 May, 2008, Wenchuan earthquake from teleseismic $P$-wave data. Teleseismic body wave observations are useful geophysical observations for estimating the overall seismic source process immediately after a great earthquake. However, it is difficult to constrain the slip vectors of later sub-events during a large earthquake such as the 2008 Wenchuan earthquake because the modeling error due to the Green's function uncertainty generally increases with time. In this study, we have applied a new waveform inversion method that incorporates the uncertainty of the Green's function, and we have assumed a simple fault plane model to evaluate our inversion scheme for a rapid analysis of the seismic source process. The results show that the slip history of the Wenchuan earthquake include six distinct sub-events. The derived source parameters were a seismic moment $M_{0}=1.4 \times 10^{21} \mathrm{~N} \mathrm{~m}\left(M_{\mathrm{w}} 8.0\right)$ and a source duration $=125 \mathrm{~s}$. The total slip vector distribution and segmentations obtained in our study are consistent with results obtained from InSAR data. The manner of the rupture propagation suggests that the two major source faults, the Beichuan fault and the Pengguan fault, intersected in the deep part of the seismogenic zone.
\end{abstract}

Key words: Waveform inversion, uncertainty of Green's function, 12 May, 2008, Wenchuan earthquake, seismic source process.

\section{Introduction}

An $M_{\mathrm{w}} 7.9$ earthquake occurred in Wenchuan County, Sichuan Province, China, on 12 May, 2008, at 06:28:01 (UTC). The U.S. Geological Survey (USGS) initially determined the earthquake to have a moment magnitude $\left(M_{\mathrm{w}}\right)$ of 8.0 and a hypocentral depth of $19 \mathrm{~km}$ at $30.986^{\circ} \mathrm{N}$, $103.364^{\circ} \mathrm{E}$. The earthquake ruptured the Longmen Shan fault zone, where a mountain front separates the Sichuan Basin to the east from the Tibetan Plateau to the west, and the difference in relief can exceed $4 \mathrm{~km}$ (Burchfiel et al., 1995). The aftershock distribution during the week after the mainshock suggests that the seismic source area extends about $280 \mathrm{~km}$ southwest and northeast from the epicenter, and the focal mechanism is consistent with the previously observed tectonic stress buildup in the Longmen Shan fault zone (Fig. 1) (e.g., Avouac and Tapponnier, 1993; Densmore et al., 2007).

Immediately after the earthquake, many seismic source models were constructed by using the teleseismic body wave data set. For example, Nishimura and Yagi (2008) performed a waveform inversion using Akaike's Bayesian Information Criterion (ABIC) and a simple data covariance matrix (Yagi and Fukahata, 2008) to estimate a seismic source model. In their model, the rupture area extended about $250 \mathrm{~km}$ northeastward from the hypocenter and the

Copy right(c) The Society of Geomagnetism and Earth, Planetary and Space Sciences (SGEPSS); The Seismological Society of Japan; The Volcanological Society of Japan; The Geodetic Society of Japan; The Japanese Society for Planetary Sciences; TERRAPUB.

doi:10.5047/eps.2012.05.006 source process consisted mainly of two major slip areas: a dextral-oblique thrust slip area near the epicenter and a near-pure strike-slip area from 100 to $250 \mathrm{~km}$ northwest of the hypocenter. Other studies characterized the slip distribution similarly (e.g., Ji and Hayes, 2008).

Many field investigations (e.g., Hao et al., 2009; Lin et al., 2009; Liu-Zeng et al., 2009; Xu et al., 2010) confirmed that the earthquake fault length was similar to that estimated by waveform modeling. The earthquake ruptured the surface for about $250 \mathrm{~km}$ along the Beichuan fault and for about $80 \mathrm{~km}$ along the Pengguan fault, and a similar multisegment fault model and total slip distribution were estimated by using interferometric synthetic aperture radar (InSAR) data (e.g., Hashimoto et al., 2009; Feng et al., 2010; Tong et al., 2010). The overall slip distribution obtained from teleseismic data immediately after the earthquake well explained the field study, and the InSAR analysis, results. On the other hand, both the field data and the InSAR data indicated a complex distribution of rake angles along the Beichuan fault that is inconsistent with the teleseismic waveform analysis result. Although teleseismic waves contain information about the overall moment release rate and the depth range of the rupture area, data covariance components that originate from modeling errors due to Green's function uncertainty prevent the estimation of a reasonable seismic source process without non-negative slip constraints (Yagi and Fukahata, 2011). The Green's function uncertainty may contribute to the discrepancy in the slip vector distribution between the teleseismic results and the field and InSAR data. 


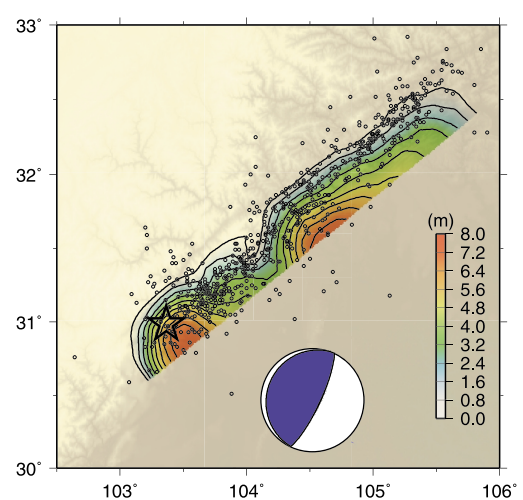

Fig. 1. Aftershocks (open circles) during the week after the mainshock, determined by the USGS, and the focal mechanism and inverted total slip distribution, determined in this study, of the 12 May, 2008, Wenchuan, China, earthquake. The star indicates the mainshock epicenter.

In general, because teleseismic wave analysis is the fastest means of estimating a source model after an earthquake, which has been an important reference for geodetic and/or geological surveys, it is important for the seismic source model estimated by using only the teleseismic data set to be reasonable. Yagi and Fukahata (2011) developed a new method of seismic waveform inversion analysis that takes into account the Green's function uncertainty in order to mitigate the effect of a modeling error due to that uncertainty. In this study, we have applied the formulation of Yagi and Fukahata (2011) to teleseismic body waves $(P$ waves) of the 12 May, 2008, Wenchuan, China, earthquake to evaluate the formulation's ability to estimate a reasonable source process, and then we have examined the rupture process in this complex fault zone.

\section{Data and Method}

We used teleseismic $P$-waveform data of the Global Seismographic Network (GSN) and Federation of Digital Seismograph Network (FDSN) downloaded from the Data Management Center of the Incorporated Research Institutions for Seismology (IRIS-DMC). We selected 44 stations from the viewpoint of data quality (Fig. 2) and used a sampling interval of $0.8 \mathrm{~s}$ to convert the teleseismic body waves into ground velocities for a waveform inversion. For the mitigation of aliasing, we applied the Butterworth low-pass filter before the re-sampling.

The spatio-temporal distribution of fault slip has been estimated by applying a multi-time window inversion to the seismic waveforms (e.g., Hartzell and Heaton, 1983). Here, we have used an inversion code developed by Yagi and Fukahata (2011) to mitigate the effect of the Green's function uncertainty. In general, an increase in the number of model parameters may lead to a solution instability, which means that even a small change in the data can affect the result. To obtain more stable results, we applied smoothing constraints to the slip distribution with respect to time and space, adopting an optimized ABIC (Akaike, 1980; Fukahata et al., 2003, 2004) to determine the smoothness parameter. So far, the non-negative slip constraint has commonly been applied in waveform inversions to obtain a plausible solution for the source process (e.g., Hartzell

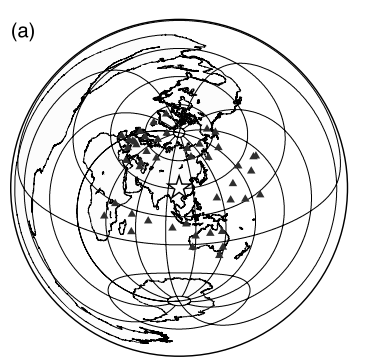

(b)

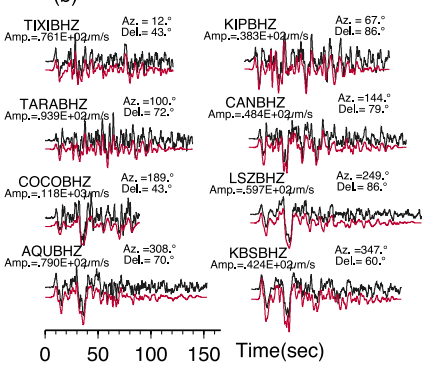

Fig. 2. Teleseismic station distribution (a) and comparison of observed and synthetic seismograms (b). In (a) the triangles indicate the global stations used in this study, and the yellow star indicates the epicenter. In (b) black and red lines indicate observed and synthetic velocity seismograms, respectively, band-passed between 0.001 and $4.5 \mathrm{~Hz}$ with a sampling rate of $10 \mathrm{~Hz}$. The station code, maximum amplitude, azimuth, and distance from the epicenter are given above each waveform.

and Heaton, 1983; Yoshida and Koketsu, 1990; Yagi et al., 2004), but a non-negative slip constraint forces a nonnegative slip distribution, even if the fault parameters or the structure model used is incorrect. In this study, we did not apply a non-negative constraint so that we could more clearly evaluate the validity of the new formulation and of our assumptions.

We calculated the theoretical Green's functions for teleseismic body waves by the method of Kikuchi and Kanamori (1991) with a sampling rate of $0.1 \mathrm{~s}$. As the structure model near the source, we used a 1D crustal model interpolated from a local structure model (Huang et al., 2008). For the $P$-wave attenuation time constant $t^{*}$, we used $1.0 \mathrm{~s}$.

We assumed that the faulting occurred on a single flat plane. We adopted the epicenter $\left(30.986^{\circ} \mathrm{N}, 103.364^{\circ} \mathrm{E}\right) \mathrm{de}-$ termined by the USGS, the hypocentral depth (about $16 \mathrm{~km}$ ) determined by Huang et al. (2008), and a fault mechanism $($ strike, dip $)=\left(231^{\circ}, 32^{\circ}\right)$ modified slightly from the moment tensor solution to be consistent with the $P$-wave amplitudes. We adopted a fault area of about $330 \mathrm{~km}$ (NE) by about $60 \mathrm{~km}(\mathrm{SW})$, which was expanded into bilinear B-splines with an interval of $10 \mathrm{~km}$ in the strike direction and $7.5 \mathrm{~km}$ in the dip direction. We also adopted a slip-rate duration of $60 \mathrm{~s}$ on each spatial knot, which was expanded into linear B-splines with an interval of $0.8 \mathrm{~s}$. The starting time of the temporal knot of the slip-rate function at each spatial knot was controlled by the rupture front velocity $V_{\mathrm{m}}$. Based on preliminary analyses, we determined $V_{\mathrm{m}}$ to be 3.2 $\mathrm{km} / \mathrm{s}$, which only controls the model space.

\section{Results}

We estimated the spatio-temporal slip distribution of the 12 May, 2008, Wenchuan earthquake by waveform inversion using $\mathrm{ABIC}$ and a data covariance matrix derived from 

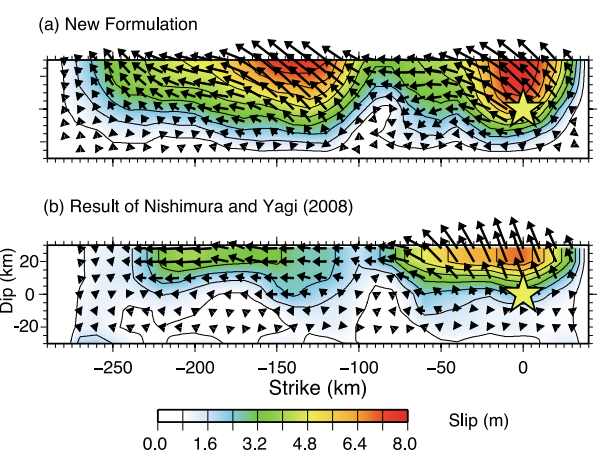

Fig. 3. The total slip distribution inverted by the present study (a) and obtained by Nishimura and Yagi (2008) (b). The star shows the hypocenter and the arrows are the slip vectors at each spatial knot.

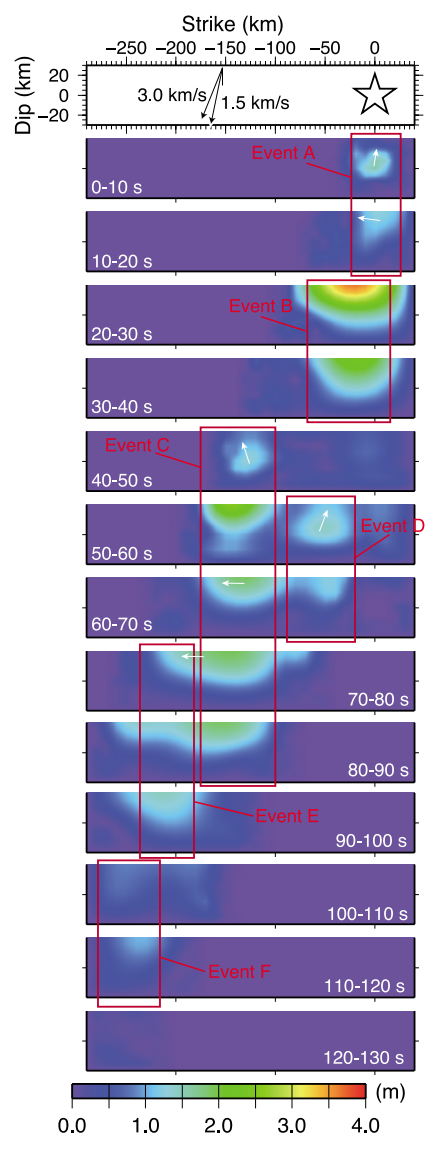

Fig. 4. Snapshots of the slip distribution at 10-s intervals. The star in the top panel represents the epicenter. The time after earthquake initiation is shown on each panel. Segments detected by the rupture evolution are shown by the red rectangles. For reference, a rupture front velocity is given with the black arrow in top panel. The white arrows show the rupture propagation direction during each time interval.

the Green's function uncertainty. The inversion results are shown in Figs. 3 and 4. Figure 3 shows the final dislocation and the slip vectors plotted on the fault plane. Figure 4 shows snapshots of the dislocation at 10 -s intervals. We found that the rupture propagated mainly to the northeast, and we detected six faulting events (Fig. 4; events A-F). In event $\mathrm{A}$, during the first $20 \mathrm{~s}$, the rupture propagated updip on a dextral-oblique thrust fault near the hypocenter. In event $\mathrm{B}$, from 20 to $40 \mathrm{~s}$ after the initial break, the rupture propagated to the northwest on a thrust fault centered about $30 \mathrm{~km}$ northeast of the epicenter. In event C (40 to $80 \mathrm{~s}$ ), the rupture propagated updip and to the northeast on a dextral-oblique thrust fault centered about $130 \mathrm{~km}$ northeast of the epicenter. In event D (50 to $70 \mathrm{~s}$ ), the rupture propagated updip on a right-lateral strike-slip fault centered about $60 \mathrm{~km}$ northeast of the epicenter. In event E (70 to $100 \mathrm{~s}$ ), the rupture propagated northeast on a right-lateral strike-slip fault centered about $210 \mathrm{~km}$ northeast of the epicenter. In event F (100 to $120 \mathrm{~s}$ ), the rupture propagated further to the northwest on a thrust fault about $250 \mathrm{~km}$ northwest of the epicenter. The rupture propagated mainly along the strike direction with an average rupture front velocity of about $2.5 \mathrm{~km} / \mathrm{s}$, and the event $\mathrm{A}, \mathrm{C}$, and D ruptures propagated updip on a shallow fault zone. The maximum slip was $8.0 \mathrm{~m}$ in segment $\mathrm{A}$. The total seismic moment was $M_{0}=1.4 \times 10^{21} \mathrm{~N} \mathrm{~m}\left(M_{\mathrm{w}}=8.0\right)$, and the total source duration was about $125 \mathrm{~s}$. We calculated synthetic velocity seismograms generated by our source model with a sampling rate of $10 \mathrm{~Hz}$, and then compared it (red) with the observed (black) velocity seismograms with a sampling rate of $10 \mathrm{~Hz}$ at typical stations and found that the waveform fit was excellent at all stations (Fig. 2(b)).

\section{Discussion and Conclusion}

First, we assumed that the faulting occurred on a single flat plane, an assumption that has been commonly applied in near-real-time analyses. The assumption means that the actual slip distribution on the Beichuan and Pengguan faults was projected onto the assumed single flat plane. Comparison of our results with those of field studies (e.g., Lin et al., 2009; Xu et al., 2010) shows that event A corresponds to a rupture on the southern Beichuan fault, event B to a rupture on the Pengguan fault, events $\mathrm{C}$ and $\mathrm{F}$ to ruptures on the middle and northern Beichuan fault, respectively, with dextral-oblique thrust faulting, and events $\mathrm{D}$ and $\mathrm{E}$ to the middle and northern Beichuan fault, respectively, with right-lateral strike-slip faulting. Under this interpretation, our results are consistent with the detailed fault slip model estimated by InSAR analysis (e.g., Feng et al., 2010; Tong et al., 2010).

The relationship between the Beichuan fault and the Pengguan fault is important for understanding the faulting system in the source region. The complex manner of rupture propagation during events $\mathrm{B}$ and $\mathrm{C}$ may contain information on the fault geometry. The rupture did not propagate to the middle Beichuan fault from the shallow part of the Pengguan fault, but rather from the deep part. This rupture propagation manner suggests that the Beichuan fault and the Pengguan fault are linked in the deep part of the seismogenic zone. This structural interpretation is consistent with a three-dimensional structural model obtained by integrating the results of geological investigations with aftershock data and seismic reflection profiles (Li et al., 2010).

The length of the Wenchuan co-seismic surface rupture zone is a matter of some dispute. Some field-based studies reported that the total length of the co-seismic surface rupture zone is only $200-240 \mathrm{~km}$, (e.g. Liu-Zhang et al., 2009; Xu et al., 2010), while others have reported that the total length of the co-seismic surface rupture zone is up to 285-300 km (e.g. Lin et al., 2009, 2010). Our slip model 
suggests that the total length of co-seismic surface rupture zone is about $300 \mathrm{~km}$, coinciding with detailed field works by Lin et al. (2012).

To estimate the seismic source process of the 2008 Sichuan earthquake, we applied a new formulation, developed by Yagi and Fukahata (2011), that introduces the Green's function uncertainty into the waveform inversion analysis. Since data covariance components derived from the Green's function uncertainty generally increase with time at each station, neglecting these covariance components results in a biased and unrealistic seismic source model (Yagi and Fukahata, 2011). A comparison of a preliminary slip distribution result obtained by Nishimura and Yagi (2008), neglecting the modeling errors due to the Green's function uncertainty, with the result obtained in this study (Fig. 3(b)) shows that the broad pattern of two major slip areas was estimated by both methods. However, the slip vectors on the northern fault plane in the Nishimura and Yagi (2008) result indicate a nearly pure right-lateral strike-slip, which is inconsistent with the field survey and InSAR analysis results. This result may thus be an artificial result due to the neglect of the Green's function uncertainty. On the other hand, the estimated slip vector on the southern segment shows a dextral slip which is still inconsistent with the field investigations (Lin et al., 2009; Xu et al., 2010). The assumption of a flat fault plane contributed to this disagreement. We also point out that the major slip distribution of Nishimura and Yagi (2008) is concentrated near the ground surface. This implies that an improper strength of spatial smoothing constrain was selected by ABIC due to the neglect of the Green's function uncertainty.

We have confirmed that a seismic source model of a great earthquake inferred from teleseismic body wave data contains useful information for understanding the overall seismic source process when the Green's function uncertainty is introduced into the waveform inversion analysis. Moreover, by comparing our seismic source model with the results of field studies, we have shown that the rupture propagation was controlled by the faulting system and the fault geometry.

Acknowledgments. The teleseismic body waves used in this study are from FDSN network stations and GSN stations and provided by IRIS-DMC. We are grateful to Guangfu Shao and Lin Aiming for their constructive comments on the manuscript. This study has been supported by the Grant-in-Aid for Scientific Research No. 24540450 of the MEXT to YY.

\section{References}

Akaike, H., Likelihood and Bayes procedure, in Bayesian Statistics, edited by J. M. Bernardo, M. H. DeGroot, D. V. Lindley, and A. F. M. Smith, pp. 143-166, University Press, Valencia, 1980.

Avouac, J.-P. and P. Tapponnier, Kinematic model of active deformation in central Asia, Geophys. Res. Lett., 20, 895-898, 1993.

Burchfiel, B. C., C. Zhiliang, L. Yuping, and L. H. Royden, Tectonics of the Longmen Shan and adjacent regions, central China, Int. Geol. Rev., 37, 661-735, 1995.

Densmore, A. L., M. A. Ellis, Y. Li, R. Zhou, G. S. Hancock, and N. Richardson, Active tectonics of the Beichuan and Pengguan faults at the eastern margin of the Tibetan Plateau, Tectonics, 26, Tc4005, doi:10.1029/2006TC001987, 2007.

Feng, G., E. A. Hetland, X. Ding, Z. Li, and L. Zhang, Coseismic fault slip of the $2008 \mathrm{Mw} 7.9$ Wenchuan earthquake estimated from InSAR and GPS measurements, Geophys. Res. Lett., 37, L01302,
doi:10.1029/2009GL041213, 2010.

Fukahata, Y., Y. Yagi, and M. Matsu'ura, Waveform inversion for seismic source processes using ABIC with two sorts of prior constraints: Comparison between proper and improper formulations, Geophys. Res. Lett., 30, 1305, doi:10.1029/2002GL016293, 2003.

Fukahata, Y., A. Nishitani, and M. Matsu'ura, Geodetic data inversion using $\mathrm{ABIC}$ to estimate slip history during one earthquake cycle with viscoelastic slip-response functions, Geophys. J. Int., 156, 140-153, 2004.

Hao, K. X., H. Si, H. Fujiwara, and T. Ozawa, Coseismic surface-ruptures and crustal deformations of the 2008 Wenchuan earthquake Mw7.9, China, Geophys. Res. Lett., 36, L11303, doi:10.1029/2009GL037971, 2009

Hartzell, S. H. and T. H. Heaton, Inversion of strong ground motion and teleseismic waveform data for the fault rupture history of the 1979 Imperial Valley, California earthquake, Bull. Seismol. Soc. Am., 73, 1553-1583, 1983.

Hashimoto, M., M. Enomoto, and Y. Fukushima, Coseismic deformation from the 2008 Wenchuan, China, earthquake derived from ALOS/PALSAR images, Tectonophysics, 491, 59-71, 2009.

Huang, Y., J. Wu, T. Zhang, and D. Zhan, Relocation of the M8.0 Wenchuan earthquake and its aftershock sequence, Sci. China Ser. D: Earth Sci., 51, 1703-1711, 2008.

Ji, C. and G. Hayes, Preliminary result of the May 12, 2008 Mw 7.9 eastern Sichuan, China earthquake, http://earthquake.usgs.gov/eqcenter/ eqinthenews/2008/us2008ryan/finite_fault.php, 2008.

Kikuchi, M. and H. Kanamori, Inversion of complex body wave-III, Bull. Seismol. Soc. Am., 81, 2335-2350, 1991.

Li, Y., D. Jia, J. H. Shaw, J. Hubbard, A. Lin, M. Wang, L. Luo, $\mathrm{H}$. Li, and $\mathrm{L}$. Wu, Structural interpretation of the coseismic faults of the Wenchuan earthquake: Three-dimensional modeling of the Longmen Shan fold-and-thrust belt, J. Geophys. Res., 115, B04317, doi:10.1029/2009JB006824, 2010.

Lin, A., Z. Ren, D. Jia, and X. Wu, Co-seismic thrusting rupture and slip distribution produced by the $2008 \mathrm{Mw} 7.9$ Wenchuan earthquake, China, Tectonophysics, 471, 203-215, 2009.

Lin, A., Z. Ren, and D. Jia, Co-seismic ground-shortening structures produced by the $2008 \mathrm{Mw} 7.9$ Wenchuan earthquake, China, Tectonophysics, 491, 21-34, 2010.

Lin, A., G. Rao, and B. Yan, Field evidence of rupture of the Qingchuan Fault during the 2008 Mw7.9 Wenchuan earthquake, northeastern segment of the Longmen Shan Thrust Belt, China, Tectonophysics, 522523, 243-252, 2012.

Liu-Zeng, Z., Z. Zhang, L. Wen, P. Tapponnier, J. Sun, X. Xing, G. Hu, Q. Xu, L. Zeng, L. Ding, C. Ji, K. W. Hudnut, and J. Can der Woerd, Co-seismic ruptures of the 12 May 2008, Ms 8.0 Wenchuan earthquake, Sichuan: East-west crustal shortening on oblique, parallel thrusts along the eastern edge of Tibet, Earth Planet. Sci. Lett., 286, 355-370, 2009.

Nishimura, N. and Y. Yagi, Rupture Process for May 12, 2008 Sichuan Earthquake (Ver. 2), http://www.geol.tsukuba.ac.jp/rnisimura/ 20080512/, 2008.

Tong, X., D. T. Sandwell, and Y. Fialko, Coseismic slip model of the 2008 Wenchuan earthquake derived from joint inversion of interferometric synthetic aperture radar, GPS, and field data, J. Geophys. Res., 115, B04314, doi:10.1029/2009JB006625, 2010.

Xu, X., X. Wen, G. Yu, G. Chen, Y. Klinger, J. Hubbard, and J. Shaw, Coseismic reverse- and oblique-slip surface faulting generated by the 2008 Mw 7.9 Wenchuan earthquake, China, Geology, 37, 515-518, 2010

Yagi, Y. and Y. Fukahata, Importance of covariance components in inversion analyses of densely sampled observed data: An application to waveform data inversion for seismic source processes, Geophys. J. Int., 175, 215-221, 2008.

Yagi, Y. and Y. Fukahata, Introduction of uncertainty of Green's function into waveform inversion for seismic source processes, Geophys. J. Int., 186, 711-720, 2011.

Yagi, Y., T. Mikumo, J. Pacheco, and G. Reyes, Source rupture process of the Tecoman, Colima, Mexico earthquake of January 22, 2003, determined by joint inversion of teleseismic body wave and near-field data, Bull. Seismol. Soc. Am., 94, 1795-1807, 2004.

Yoshida, S. and K. Koketsu, Simultaneous inversion of waveform and geodetic data for the rupture process of the 1984 Naganoken-seibu, Japan, earthquake, Geophys. J. Int., 103, 355-362, 1990.

Y. Yagi (e-mail: yagi-y@geol.tsukuba.ac.jp), N. Nishimura, and A. Kasahara 